\title{
CARRERA JUDICIAL. LINEAMIENTOS GENERALES PARA UN ESTATUTO PROFESIONAL DEL JUEZ
}

\author{
Judicial Career. General guidelines for a professional statute of the judge
}

María Francisca Zapata García*

Resumen: Se propone una reformulación de la Carrera Judicial a fin de garantizar la expedición de una decisión jurisdiccional con sujeción a la ley, que integre al proceso de decisión los deberes éticos de la función de juzgar. El modelo supone la superación de la actual relación biunívoca entre categorías y cargos para avanzar hacia una relación unívoca (no recíproca) entre las dimensiones del Escalafón Funcionario y Función Jurisdiccional. Para ello se presenta un Sistema de Carrera con residencia exclusiva en el Escalafón Primario ordenada por categorías y constitutivo de un régimen de profesionalización, que implica que el acceso, desplazamiento y permanencia en las categorías se hace depender de los subsistemas de Capacitación y de Gestión del Desempeño -este último orientado por una matriz ética-, que desarrolla regímenes de evaluación del desempeño y disciplinario de ultima ratio.

Palabras clave: carrera judicial - capacitación judicial - evaluación del desempeño disciplina judicial.

Abstract: The restructuring of the judicial career is proposed, in order to ensure that judicial decisions are made in accordance with the law, thereby assuring that the judicial decision making process embodies the ethical duties of the judicial function. The model demands the supersession of the current biunivocal relation between categories and positions in favor of a univocal relation (not reciprocal) between the judicial structure, on the one hand, and the administrative, on the other. To that end, an exclusive career system for judges is presented, organized by category and constitutive of a regime of professionalization. In this system, access to and continuance in a category depends on professional training and accountability subsystems -the latter organized around an ethical core-, with performance evaluations and disciplinary responses as a last resort.

Keywords: judicial career - judicial training - performance evaluation - judicial discipline.

\section{Introducción}

Lo que hoy solemos entender por Poder Judicial en Chile encaja, con un alto grado de ortodoxia y casi sin contratiempos, en lo que la teoría denomina -de las más

\footnotetext{
* Abogada, licenciada en ciencias jurídicas y sociales de la Universidad de Chile; Diploma Reforma Procesal Penal, Universidad Diego Portales; Diploma Docencia Jurídica, Universidad Católica del Norte; Magister en Gobierno y Sociedad, Universidad Alberto Hurtado. Jueza de Garantía Santiago. Correo electrónico:mfzapata@pjud.cl.
}

Este artículo fue recibido el 11 de diciembre de 2012, siendo aprobada su publicación con fecha 12 de abril de 2013. 
Zapata - Carrera judicial. Lineamientos generales para un estatuto...

variadas formas y aludiendo al mismo fenómeno organizacional- modelo napoleónico, piramidal, jerárquico o tecnoburocrático de organización de la magistratura. ${ }^{1}$

Esto implica que la configuración actual del Poder Judicial chileno se corresponde con una heredada constitución monárquica que se ha mantenido, en lo fundamental, estable desde la Colonia hasta nuestros días. En esto seguimos a Aldunate, ${ }^{2}$ quien a nuestro juicio ha descrito con precisión la (no) evolución estructural del Poder Judicial chileno. En sus palabras: nuestro sistema judicial conserva, en lo esencial de su constitución, los rasgos de la judicatura monárquica existente a la fecha del advenimiento de la República, sin que, en ya casi 200 años de evolución institucional, haya sido sustancialmente modificado, salvo en lo que dice relación con la dependencia respecto del monarca como jefe del ejecutivo. La permanencia del modelo hace que sus consecuencias negativas hayan sido asimiladas por el sistema institucional, al punto que ni siquiera se discuten las deficiencias que este modelo plantea para la vigencia efectiva de un Estado de Derecho. $^{3}$

La organización de la judicatura se asienta en las siguientes notas estructurales: a) la carrera por ascensos en formato de yuxtaposición de las dimensiones compuestas por los cargos judiciales y las categorías del escalafón; b) los dispositivos orgánicos de control o disciplinantes que distribuyen (o amenazan con distribuir) los reproches pertinentes a la conducta y desempeño funcionario; c) el sistema de nombramientos y promociones en contextos de amplia discrecionalidad; y c) la congestión en la cúspide o concentración de funciones jurisdiccionales y de gobierno en los niveles superiores de la estructura.

La principal crítica al modelo vigente derivado de la conjugación de estas notas estructurales apunta a que no existen garantías institucionales que aseguren el cumplimiento de la función judicial central, esto es, la expedición de una decisión sujeta estrictamente a la ley, sino que, lejos de eso, se constata la existencia de institutos que apuntan en el sentido contrario y que constituyen interferencias a la vinculación del juez a la ley. Lo mismo ocurre en relación con los deberes periféricos, esto es, los deberes éticos de la función de juzgar.

Esta apreciación se basa, en síntesis, en la constatación de que el sistema de controles posee una relación binaria con el sistema de nombramientos y promociones -articulada por la Lista de Méritos que da cuenta de la (in)conducta anual del funcionario- $\mathrm{y}$ ambos se caracterizan por la discrecionalidad que posee el

\footnotetext{
1 Flores, Álvaro: “Gobierno Judicial: el caso chileno. La reforma olvidada”. Revista de Estudios de la Justicia 6, 2006, p. 128.

2 Aldunate Lizana, Eduardo: "La constitución Monárquica del Poder Judicial". Revista de Derecho de la Universidad Católica de Valparaíso, XXII, 2001, pp. 193.

3 Ibid, p. 205.
} 
superior que controla disciplinariamente y posee poder de promoción en función del ejercicio de sus facultades de gobierno. Y si se suma a ello que estas facultades de gobierno se encuentran depositadas en los mismos agentes que revisan cotidianamente las decisiones de los jueces/candidatos a promoción la precariedad del modelo es evidente, pues nada puede asegurar que la decisión del subordinado (muy probablemente interesado en obtener una promoción) no sea una decisión estratégica que lo lleve a fallar, ante todo, según el criterio jurídico del superior. El modelo organizacional, entonces, permite (y propicia) los cálculos de conveniencia en relación con las expectativas de carrera, erosionando gravemente las condiciones de probabilidad de un juzgar independiente.

La reformulación de la organización de la judicatura que se propone parte justamente de la constatación de estos defectos estructurales, por lo que exige:

Sistema de Carrera Funcionaria basado en categorías del escalafón vinculadas unívocamente con los cargos judiciales asentado en:

a) Subsistema de capacitación

b) Subsistema de gestión del desempeño

Sistema de Nombramientos por méritos/antigüedad en cargos vacantes

$>$ Sistema de Gobierno Judicial en manos de un órgano distinto de la Corte Suprema.

A nuestro juicio, estos arreglos institucionales traducen la funcionalidad de la organización estructural que buscamos para la labor judicial.

Por razones de espacio solo esbozaremos los lineamientos generales para un nuevo Sistema de Carrera Funcionaria que proponemos basado en categorías del escalafón vinculadas unívocamente con los cargos judiciales asentado en dos subsistemas, uno de capacitación y otro de gestión del desempeño.

Para presentar nuestra reflexión asumiremos que el ejercicio de la función judicial se manifiesta en un proceso decisional que hace posible -o al menos útilla distinción entre centro y periferia.

El centro o núcleo duro de la función judicial es o importa una decisión que tiene una finalidad: dar a cada uno lo que en derecho corresponde. Mirado de revés no es o no importa una decisión que pueda integrar una finalidad ajena a dar a cada uno lo que en derecho corresponde. Decimos con Atria que en nuestras condiciones postmetafísicas la determinación de qué es lo que a cada uno corresponde no puede descansar ni en la naturaleza, ni en la religión ni en la tradición. Por consiguiente, la única forma de fundar la determinación de qué es lo suyo de cada cual, es en las normas que hemos aceptado como nuestras, es decir, la legislación. ${ }^{4}$

${ }^{4}$ Atria, Fernando: “La improbabilidad de la jurisdicción”. La Judicatura como organización, 2007, p. 36. 
Zapata - Carrera judicial. Lineamientos generales para un estatuto...

La periferia abarca el conjunto de deberes que se presupone acompañen el proceso decisional y que universalmente se identifican como los deberes éticos de la función de juzgar. Su integración (o no) al circuito de la decisión nos permitirá hablar de un proceso decisional de mayor o menor calidad.

Como es fácil advertir, sostenemos que la descripción de la tarea del juez no se agota en la frase que alude a la decisión del caso conforme a la ley, aun cuando ello constituye el centro o núcleo duro de la función. ${ }^{5}$ Para definir a cabalidad lo judicial debemos considerar los deberes inherentes a la función de juzgar que indefectiblemente son requeridos en las diferentes fases del proceso decisorio y que determinan, según su nivel de (in)cumplimiento, una mayor o menor calidad final del mismo.

Esta distinción (centro/periferia) nos permite visualizar con nitidez los estatutos diferenciados que deben aplicarse respecto de las distintas dimensiones de la función judicial. Así, el centro de la función judicial, esto es, la decisión jurisdiccional, debe ser regido por el principio de independencia que reconoce como único referente a la ley, a la vez que debe ser limitado exclusivamente por el sistema de responsabilidad penal originada en el apartamiento doloso y/o culposo de la misma. Se excluirán en nuestro modelo sistemas de responsabilidad que no sean penales en relación con la decisión jurisdiccional, estimándose como únicamente procedentes para su control los sistemas recursivos de mayor o menor amplitud según la opción que tome el ordenamiento jurídico determinado.

La periferia de la función judicial, constituida por la suma de los deberes éticos de la función de juzgar que participan del proceso decisional permite, por el contrario, la existencia de múltiples controles, a los cuales puede asociarse una variada gama de consecuencias según el modelo de responsabilidad disciplinaria a emplearse por el respectivo diseño organizacional. Es en este área donde han de ubicarse los sistemas de evaluación del desempeño y los regímenes disciplinarios, de cuya eficacia dependerá a la larga la calidad final del proceso decisional.

\section{Sistema de Carrera basado en categorías del escalafón vinculadas unívocamente con los cargos judiciales}

En el modelo vigente de Carrera Judicial, la Función Jurisdiccional y el estatuto del funcionario expresado en el Escalafón van unidos al modo de los vidrios dobles de

\footnotetext{
${ }^{5}$ Cuando hablamos del juez sujeto únicamente a la ley, no se está defendiendo una concepción de aplicación mecanicista, Ver Atria, Fernando: "Jurisdicción e Independencia Judicial. El Poder Judicial como Poder Nulo", Revista de Estudios de la Justicia, 2005, p. 128.
} 
REJ - Revista de Estudios de la Justicia - No 18 - Año 2013

una ventana de seguridad. A ello nos referimos cuando decimos que la carrera judicial se encuentra en un formato de yuxtaposición.

Esta yuxtaposición surge de la correspondencia biunívoca existente entre los cargos judiciales y las categorías del escalafón.

Se llama correspondencia biunívoca a la que existe o se establece entre los elementos de dos conjuntos cuando además de ser unívoca (cada elemento del primer conjunto corresponde inequívocamente a un elemento del segundo) es recíproca (a cada elemento del segundo corresponde sin ambigüedad uno del primero). Esto sucede exactamente entre cargos y categorías. Si los cargos son los elementos de nuestro primer conjunto y las categorías del segundo, se puede observar que la relación es unívoca, pues a cada elemento del primero (cargo) corresponde inequívocamente a un elemento del segundo (categoría) y además es recíproca, pues a cada elemento del segundo (categoría) corresponde, sin ambigüedad, uno del primero (cargo).

De este modo, si en un momento dado el número total de cargos predefinidos para jueces por el Código Orgánico de Tribunales se encuentran ejercidos por sus respectivos titulares, es posible advertir la existencia de una perfecta doble pirámide en la que cada operador posee una doble identidad, en que tal cargo judicial (tal función) corresponde a tal categoría en el escalafón de funcionarios. Dicho de otra manera, si el funcionario posee una determinada categoría se debe a que ha sido nombrado en determinado cargo y ese es el cargo que ejerce y no otro.

Proponemos un modelo que sustituye el formato de carrera de yuxtaposición bidimensional por un diseño de carrera judicial basado en categorías vinculadas unívocamente a los cargos judiciales. La diferencia con el modelo actual radica en el tipo de relación a establecer entre cargos y categorías, la que es unívoca, en el sentido de que a cada cargo le corresponde inequívocamente una categoría que pasa a ser parte de sus presupuestos de nombramiento y ejercicio. Pero no es recíproca, pues a las categorías adquiridas no corresponde necesariamente el nombramiento y ejercicio del cargo de esa categoría.

Como es posible observar, no se pretende la "abolición de la carrera", aun cuando se abandona el sentido clásico de la expresión que alude al modelo tecnoburocrático y jerarquizado de corte weberiano, sino que se aboga por su reformulación, encaminada a la configuración de un nuevo estatuto para el desarrollo de la vida laboral del juez, basado en su profesionalización.

Para presentar los lineamientos generales del nuevo modelo de Carrera Judicial seguiremos con la distinción de las dos dimensiones anotadas. Nos referiremos en primer lugar a la dimensión de la Función Jurisdiccional articulada por los cargos judiciales y sus notas centrales. Luego desarrollaremos la dimensión 
Zapata - Carrera judicial. Lineamientos generales para un estatuto...

estatutaria que constituye la Carrera propiamente tal, articulada sobre la base de las diferentes categorías del escalafón.

\section{a. La Función Jurisdiccional y los cargos judiciales}

La noción nuclear de la propuesta es la articulación del sistema de carrera sobre la base de una relación unívoca, esto es, una vinculación no recíproca entre cargos judiciales y categorías.

Vargas ha descrito esta idea señalando que es necesario desvincular el grado que el magistrado tenga en la carrera judicial con la posición que ocupa en determinada instancia procesal ${ }^{6}$, en el entendido que con la expresión "grado" se ha querido aludir a "categoría" -terminología usada por el Código Orgánico de Tribunales para referirse a la posición del juez en la carrera judicial-, estamos hablando de lo mismo. En nuestro estudio, sin embargo, se desecha la expresión "desvincular categoría de cargos judiciales", pues dicha afirmación no da cuenta de la doble vinculación (o correspondencia biunívoca) entre categorías y cargos, y de la subsistencia en el diseño propuesto de una de ellas: la relativa al requisito de contar con determinada categoría para determinados cargos. La subsistencia de esta vinculación es la que nos lleva a hablar de una vinculación unívoca, esto es, no recíproca.

De cualquier forma, ambas ideas primariamente tienden a separar las dos dimensiones que en los modelos tradicionales corren yuxtapuestas.

La razón sustantiva que inspira un diseño que distingue explícitamente ambas dimensiones radica en que el escalafón admite -y de hecho se sustenta encriterios diferenciadores, pues opera sobre la base de distintos niveles (categorías) de los que derivan prerrogativas de diferente naturaleza y entidad para los respectivos funcionarios. Por el contrario, la dimensión de la función jurisdiccional bien entendida no admite más diferenciación que la funcional, esto es, la relativa a las diversas y específicas tareas, pues ellas son expresión de un mismo poder soberano. En consecuencia, no cabe hablar de jueces superiores ni inferiores, sino que solo de jueces que ejercen labores diversas, en distintas competencias y/o diferentes grados jurisdiccionales.

La dimensión netamente jurisdiccional está regida por la igual dignidad de la función, lo que conlleva la igual dignidad de quienes ejercen la magistratura. Tan juez es quien resuelve casos como titular de un cargo de juez de familia como el juez que resuelve casos de la misma materia como titular de un cargo en la Corte

\footnotetext{
6 Vargas, Juan Enrique: "Alternativas para estructurar el gobierno judicial respetando la independencia de los jueces", en La Judicatura como organización, 2007, p. 116.

7 La Constitución italiana dispone en su artículo 107: Los magistrados se distinguirán entre sí solamente por la diversidad de sus funciones. Una norma de este tipo puede servir de base para una reforma estructural en el sentido que proponemos.
} 
Suprema. La horizontalidad, entonces, es un principio fundamental en nuestra propuesta de organización de la judicatura en lo tocante a la dimensión que compete al ejercicio de la función jurisdiccional y, conforme a este, ningún juez o tribunal será considerado como inferior o superior a otro. ${ }^{8}$

En consonancia con el principio de horizontalidad en la función, estimamos imprescindible aludir a cada uno de los cargos bajo la expresión única de juez, a la que se sumará la naturaleza del tribunal. Así, el operador en lo tocante a su función será denominado como juez del tribunal respectivo: juez de garantía, juez de familia, juez laboral, juez civil, juez de corte de apelaciones, juez de corte suprema, pues todos estos operadores ejercen jurisdicción con igual dignidad y se hallan sometidos a la misma exigencia de un estado democrático de derecho, esto es, a la independencia, que significa sujeción a la ley.

Pero también contamos con una razón "operativa" para impulsar nuestra propuesta y es la necesidad de permitir el desplazamiento de los jueces mediante las diversas categorías del escalafón, sin que ello dependa -a ciertos niveles- de la existencia real de cargos vacantes, generando un mejoramiento sostenido de la calidad de los recursos humanos a través de la alianza entre un adecuado régimen de capacitación y un eficiente sistema de evaluación del desempeño.

No puede pasarse por alto en el análisis el fenómeno acaecido con ocasión de las reformas procesales producidas durante la última década ${ }^{9}$, que ha aumentado el número de jueces en la base al punto que la pirámide se ha visto notablemente aplanada, pese a que conserva su forma de tal. Vargas señalaba en el año 2007 que en 1999 había en Chile 376 jueces de primera instancia, cantidad que en 2007 se elevó a 1.290. El número de Ministros de Cortes de Apelaciones en ese período varió en una proporción mucho menor: de 140 a 155. Esto significa que si en 1999 había en Chile 2,7 jueces de primera instancia por cada 1 Ministro de Corte de Apelaciones, hoy existen 8,3. ${ }^{10}$ Actualizando los datos nos encontramos con una realidad todavía más acuciante, ya que hoy figuran en el Escalafón Primario 193 funcionarios en la segunda categoría (ministros de Cortes de Apelaciones y fiscales judiciales) y 1.605 funcionarios en el resto de las categorías.

Esto implica que para muchos jueces la "carrera" judicial en la práctica se iniciará y probablemente terminará en la primera instancia, lo que si bien no constituye un defecto en sí mismo, es un fenómeno que genera externalidades negativas incontestables. La primera, la falta de incentivos para mejorar en un

\footnotetext{
${ }^{8}$ Esta idea está desarrollada radicalmente en el Anteproyecto de Nuevo Código de Organización Judicial del Paraguay (Centro de Estudios Judiciales, 2009) al disponer en su artículo 6, tras la implantación del principio de horizontalidad, que "la ley identificará y nombrará a los jueces y tribunales en función a su competencia, quedando prohibida cualquier identificación de denote supremacía, superioridad o rangos de jerarquía entre los jueces o tribunales".

${ }^{9}$ Reformas procesal penal, de familia y laboral.

${ }^{10}$ Vargas, Juan Enrique: op. cit., p. 112.
} 
Zapata - Carrera judicial. Lineamientos generales para un estatuto...

sistema que no ofrece reconocimiento. La segunda, estrictamente relacionada con la anterior, la imposibilidad de generar un universo de recursos humanos en condiciones acreditadamente óptimas para acceder a las funciones más sensibles o de mayor especialización.

\section{b. El Escalafón de funcionarios judiciales y sus categorías}

En el diseño que proponemos la carrera es un sistema de perfeccionamiento profesional para los funcionarios que ejercen jurisdicción, articulada por los subsistemas de Capacitación y de Gestión del Desempeño que desarrolla regímenes de evaluación del desempeño y disciplinario de ultima ratio.

La Carrera Judicial se desarrolla en el Escalafón Primario que se encuentra dividido en categorías que ordenan el universo de jueces en distintas posiciones, con sujeción a una serie de reglas relativas al ingreso al Escalafón, a su permanencia, desplazamiento y separación, reglas que en conjunto dan lugar a un estatuto profesional que garantiza estabilidad y profesionalización.

El acceso a cada una de las categorías exige una serie de requisitos relativos a permanencia en la categoría anterior, capacitación y desempeño, y proporcionan al juez que accede a ellas diversas prerrogativas estatutarias y las habilitaciones predeterminadas para postular a determinados cargos vacantes, según las exigencias propias de la relación unívoca entre cargo-categoría.

En el modelo actual los jueces (titulares y subrogantes) figuran en el Escalafón Primario de Funcionarios Judiciales ${ }^{11}$ en siete categorías y avanzan desde la séptima a la primera categoría. A las diversas categorías se asocian prerrogativas diferenciadas relativas a remuneraciones y trato. Dentro de las respectivas categorías se coloca a los funcionarios por orden estricto de antigüedad, según las fechas de sus nombramientos en propiedad. A los diferentes cargos judiciales, por su parte, corresponde una diferente función según materia o grado jurisdiccional en que conoce el juez respectivo.

En este sistema se produce entre los cargos judiciales y las categorías una relación biunívoca, por lo que teniendo los jueces siete categorías para moverse en sentido ascendente, para hacerlo deben lograr ser nombrados en propiedad en aquellos cargos que guardan correspondencia recíproca, de tal modo que para obtener, por ejemplo, la segunda categoría es preciso ser nombrado juez de Corte de Apelaciones. En un modelo como este, cabe preguntarse qué es lo que interesa al juez que intenta el ascenso: si la categoría y las prerrogativas asociadas, o la función a desarrollar según el nuevo cargo judicial en que será nombrado.

En nuestra propuesta el Escalafón de Funcionarios está compuesto también de categorías a las que se asocian determinadas prerrogativas al igual que

11Artículos 264, 265, 266 y 267 del Código Orgánico de Tribunales. 
en el modelo vigente. También existe correlación entre categorías y cargos judiciales, pero esta relación es unívoca, es decir, existe vinculación pero no es recíproca. Esto significa que para ser juez de Corte de Apelaciones se requiere poseer la Segunda Categoría, sin embargo, quien posee la Segunda Categoría podría estar ejerciendo perfectamente un cargo de juez de Tribunal Oral en lo Penal o cualquier otro similar. Lo anterior sucedería si el funcionario logra adquirir la Segunda Categoría producto del resultado exitoso de un proceso de acreditación de las habilitaciones exigidas, esto es, determinado nivel de capacitación y ciertos resultados de desempeño y no haber postulado (por desinterés vocacional, por ejemplo) al cargo de juez de Corte de Apelaciones. La ventaja de nuestro modelo es que descansa sobre la idea base de permitir el desplazamiento por las diversas categorías con prescindencia de la existencia de vacantes de cargos conectados unívocamente a dichas categorías.

Usemos un ejemplo que nos es familiar en el actual esquema. Quien posee la Tercera Categoría y desea ascender a la Segunda puede optar, si cuenta con los presupuestos de antigüedad y habilitaciones pertinentes, a un cargo vacante de ministro de Corte de Apelaciones, fiscal judicial, relator o secretario de la Corte Suprema. Es decir, el interesado posee más de una opción, pero es requisito sine qua non que exista ese cargo vacante y se produzca el nombramiento en propiedad. De este nombramiento se deriva la expiración del cargo anterior ${ }^{12}$ y tras el juramento de rigor se asume el ejercicio de las funciones del nuevo cargo. En el modelo que proponemos quien posee la Tercera Categoría y desea ascender a la Segunda puede hacerlo si cuenta con los presupuestos de antigüedad y acredita las habilitaciones pertinentes (de capacitación y desempeño) con prescindencia de la existencia o no de un cargo vacante que guarde correlación con la Segunda Categoría. De este modo, una mejor categoría se busca -y obtiene si es el casodirectamente, sin mediación de cargo alguno, por lo que puede haber promoción en la categoría sin que exista necesariamente promoción en el cargo. Así, la obtención de una mejor categoría no implica necesariamente la expiración del cargo que ejerce el interesado. Por ello sostenemos que nuestro modelo es vocacional, ya que en caso alguno el interés del juez por el nombramiento en un cargo puede justificarse únicamente en la pretensión de mejores prerrogativas, las que puede obtener sin moverse de su propio cargo.

Para hacer de la carrera un sistema de profesionalización orientado al mejoramiento continuo de los funcionarios judiciales, el motor del modelo es la acreditación de las habilitaciones que miran por un lado a la capacitación (formación) del juez y por otro a los resultados periódicos de su evaluación del desempeño.

El diseño del modelo debe contemplar brechas significativas entre los diversos niveles que representan las categorías, con tendencia a crecer a medida

\footnotetext{
12 Artículo 332. El cargo de juez expira: $7^{\circ}$ por la promoción del juez a otro empleo del orden judicial aceptado por él.
} 
Zapata - Carrera judicial. Lineamientos generales para un estatuto...

que del nivel respectivo se derivan mayores prerrogativas. Al mismo tiempo debe hacer una labor de contención, sobre la base de diversas estrategias (incentivos) para evitar el desplazamiento masivo hacia los niveles más altos. En este esquema, no se constriñe al juez a postular a cargos ajenos a su preferencia vocacional para obtener mejores prerrogativas. Las ventajas son evidentes: favorece la especialización y la permanencia en los cargos por vocación. Al mismo tiempo, la puerta abierta a mejores categorías constituye un buen acicate para el esfuerzo del juez por más capacitación y mejor desempeño.

\subsection{Subsistema de Capacitación}

La Academia Judicial ${ }^{13}$ tiene como finalidad la formación de los postulantes a Cargos del Escalafón Primario del Poder Judicial y el perfeccionamiento de todos los integrantes de dicho poder del Estado.

El programa de formación para postulantes a Cargos del Escalafón Primario del Poder Judicial tiene como objetivo capacitar a los abogados ${ }^{14}$ interesados en abrazar la carrera judicial en las competencias, destrezas y criterios básicos para desempeñar sus funciones. La aprobación de este programa es requisito indispensable para ingresar al Escalafón Primario del Poder Judicial, salvo que al llamado a segundo concurso por el mismo Cargo no se presenten postulantes con este requisito.

\footnotetext{
${ }^{13}$ Academia Judicial de Chile fue creada por la Ley $\mathrm{N}^{\circ} 19.346$ de 18 de noviembre de 1994. Es una corporación de derecho público, está dotada de personalidad jurídica y patrimonio propio y está sometida a la supervigilancia de la Corte Suprema. La dirección superior y administración de la Academia Judicial está a cargo de un Consejo Directivo, presidido por el Presidente de la Excma. Corte Suprema, o quien lo subrogue. Lo integra, además, el Ministro de Justicia, quien puede hacerse representar por el Subsecretario de la cartera, un Ministro de la Excma. Corte Suprema, elegido por esta en única votación, el Fiscal de la Excma. Corte Suprema, un Ministro de Corte de Apelaciones elegido, en única votación, por los funcionarios de la segunda Categoría del Escalafón Primario del Poder Judicial, un miembro de la segunda Categoría del Escalafón Primario del Poder Judicial elegido por la directiva de la asociación gremial de carácter nacional que reúna al mayor número de integrantes de dicho Escalafón Primario, un representante de las asociaciones gremiales de abogados existentes en el país, elegido por sus Presidentes, de entre ellos; y dos académicos con más de cinco años de docencia universitaria, designados por el Presidente de la República, con acuerdo del Senado.

${ }^{14}$ El llamado a presentar postulaciones será público y comunicado mediante un aviso en el Diario Oficial y otro en un diario de circulación nacional, los que deberán publicarse con no menos de noventa días de anticipación a la fecha de cierre de la recepción de solicitudes de ingreso. La selección consultará el análisis de los antecedentes de los candidatos, debiendo asignarse especial importancia a sus estudios y calificaciones universitarios. Durante el proceso de selección se someterá a los postulantes a exámenes psicológicos, de aptitudes y de conocimientos. En caso de que estos últimos sean escritos, se garantizará el anonimato en la evaluación. El resultado del proceso de selección no será susceptible de recurso alguno. El postulante que no fuere seleccionado podrá presentarse a nuevas convocatorias.
} 
Una vez en propiedad de un Cargo del Escalafón Primario el funcionario se relaciona con la Academia Judicial por los cursos anuales que esta debe proveerle y que conforman el plan de perfeccionamiento de los integrantes del Poder Judicial, que tiene por finalidad profundizar y actualizar los conocimientos en materias propias de su desempeño.

Cada funcionario debe postular a estos cursos anuales, lo que constituye un requisito para integrar la Lista de Méritos. ${ }^{15}$ De este modo se conecta esta exigencia de capacitación anual con la Carrera, pues la (no) inclusión en esta lista es fundamental a la hora de la (no) inclusión en terna o quina en el proceso de postulación a un Cargo vacante. De cualquier forma su importancia real es muy menor, pues la exigencia se encuentra referida a la postulación al curso y no a la participación efectiva en él, ni menos a los resultados por su evaluación, ya que estos cursos solo exigen asistencia y no evaluación de los alumnos.

Atención aparte merece el Programa de Perfeccionamiento Profesional para optar a los cargos de ministro de Corte de Apelaciones que la Academia debe impartir directa y periódicamente. El Programa debe contemplar diversos aspectos de derecho sustantivo y procesal, así como los conocimientos y destrezas habilitantes para el cumplimiento de las funciones de ministro de Corte, incluyendo las de fiscalización que el Código Orgánico de Tribunales les encomienda. Si existieren más postulantes que cupos, tendrán prioridad los funcionarios que tengan cumplidos los demás requisitos para figurar en terna. En caso de igualdad, se estará a la última calificación anual y, si persistiere la igualdad, primará la categoría y, dentro de esta, la antigüedad. Esta regla de prelación ha llegado a tener, contingentemente, muchísima importancia, pues como señalamos la Carrera Judicial sufre un colapso a partir de las reformas procesales que han hecho crecer significativamente el número de cargos hasta la Tercera Categoría, sin que sucediera lo mismo con los cargos de Segunda.

No es mucho más lo que podemos decir sobre la Academia Judicial y su repercusión en la Carrera Judicial vigente a casi veinte años de su creación ${ }^{16}$, pues las capacitaciones de los miembros del Escalafón Primario no cumplen ningún rol de importancia, salvo en lo tocante al Programa de Perfeccionamiento para optar al cargo de ministro de Corte de Apelaciones y que constituye la puerta de entrada al ascenso.

En nuestro modelo la capacitación profesional es la médula de la estructura que articula el avance en el desarrollo de la vida laboral. Como adelantamos, la Carrera Judicial se desarrolla en niveles o categorías que estimamos deben

\footnotetext{
${ }^{15}$ Para ser calificado en lista de mérito, todo funcionario, salvo los de Primera Categoría, deberá haber postulado cada año a actividades de perfeccionamiento de la Academia.

${ }_{16}$ Sin que lo dicho implique desconocer el relevante rol que tuvo en sus inicios para instalar un mecanismo de selección para el ingreso al servicio judicial basada en los méritos de los postulantes, en un contexto de igualdad de oportunidades.
} 
Zapata - Carrera judicial. Lineamientos generales para un estatuto...

duplicarse al menos en relación con el número existente, pues un modelo que contenga muchos niveles o categorías desdramatiza la competencia y consigue que la posición de cada uno en el Escalafón sea asunto de cada uno, sin que exista la constricción al ascenso. Se aspira, de hecho, a que a la larga la idea del movimiento del juez se entienda como desplazamiento en la carrera más que ascenso en la misma, impulsada por los grados o niveles de capacitación alcanzados y resultados de desempeño conseguidos.

Proponemos que la categoría de acceso al sistema judicial sea la Primera Categoría y no al revés, pues estimamos que ello contribuye a despejar el sistema del indeseado ambiente de superioridad/inferioridad que define el diseño vigente para pasar a un régimen en el que el nivel o la categoría se asocie a más y mejor, más capacitación y mejor desempeño.

A la Primera Categoría proponemos que debe ingresar por derecho propio el alumno de la Academia Judicial que ha aprobado el Programa de Formación para postular a cargos del Escalafón Primario del Poder Judicial, a fin de conectarlos desde el principio con el funcionamiento del sistema y apoyarlos en el camino que acaban de iniciar con un eficiente sistema de asignación de suplencias e interinatos, y así sacar a este valioso recurso de la verdadera orfandad que sufre en la actualidad una vez que abandona la Academia Judicial.

A la Segunda Categoría debieran ingresar los jueces que adquieran en propiedad cualquier cargo de juez de la República, mediante el respectivo nombramiento y desde esta posición debiera avanzarse -según el interés del funcionario- en el desplazamiento por las diversas categorías.

Para la configuración de las categorías debiera pensarse, a partir de algún nivel, en el desarrollo de las especializaciones. No es casual que desde un tiempo a esta parte se hayan creado ${ }^{17}$ tribunales especializados en diversas materias de alta complejidad técnica. No parece posible discutir que la razón detrás de esta decisión de política pública es el escepticismo en relación con la posibilidad de que los miembros ordinarios de la judicatura pudieren conocer y resolver dichos asuntos adecuadamente, atendidas las altas exigencias técnicas para la comprensión de los temas involucrados. Y si bien este camino de los tribunales especializados puede ser una opción válida, no es menos cierto que es imposible sustraer del todo estas materias a la judicatura ordinaria. La sola posibilidad de que con ocasión de dichas materias se cometan ilícitos penales exige que los jueces llamados a tomar las decisiones relativas a la responsabilidad penal estén a la altura exigida por la especificidad de que se trate, especialmente si de sus decisiones se siguen consecuencias para la restricción de la libertad de las personas. Por lo demás, estos asuntos suelen resolverse en último término en las Cortes de Apelaciones o en la Corte Suprema.

\footnotetext{
${ }_{17}$ Tribunales Tributarios y Aduaneros, Tribunal de la Libre Competencia, Tribunales Ambientales, entre otros.
} 
Si se tiene unas diez o quince categorías deben fijarse reglas que permitan a los jueces desplazarse por ellas en busca de mejores prerrogativas. Los puntos o créditos para lograrlo estarán en consonancia directa con las horas de capacitación que el juez certifique en las materias disponibles. Es posible crear una buena malla de opciones a tomar por quienes se consideren motivados a seguir por las diversas rutas de especializaciones o profundizaciones de materias y toda esta labor debería recaer en manos de la Academia Judicial que pasaría a tener un rol preponderante en la Carrera de los jueces.

\subsection{Subsistema de gestión del desempeño}

El mayor defecto del sistema vigente de control consiste en que la operativa de estos dispositivos hace recaer sus efectos tanto en el área central ${ }^{18}$ como en la periférica de la función judicial. Sobre la base de esta notoria y notable falencia es posible calcular el demoledor perjuicio para las condiciones de probabilidad de un ejercicio jurisdiccional independiente, en que la independencia es garantía de sujeción a la ley. De otra parte y también como consecuencia directa del hecho de la preeminencia del control sobre el núcleo central de la función, se produce una insuficiencia en la atención de los deberes periféricos, desincentivando un proceso decisorio de calidad.

En nuestro modelo solo los deberes periféricos serán gestionados por el subsistema, por lo que se excluye explícitamente todo mecanismo, instituto o herramienta dirigida a controlar el núcleo central de la función judicial, esto es, la decisión jurisdiccional.

El modelo de gestión del desempeño se orienta por una matriz ética y funciona sobre la base de un diseño bipartito que contempla dos regímenes: a) de evaluación del desempeño y b) disciplinario. Se basa en el establecimiento de un conjunto de deberes periféricos pero inherentes a la función de juzgar, que universalmente son identificados como principios de ética judicial.

Este modelo implica en su primer régimen "trabajar" cada uno de los deberes éticos en clave de evaluación del desempeño, levantando indicadores del cumplimiento de dichos deberes junto a los medidores respectivos, en un sistema que admita una variación evolutiva.

La ventaja consiste en su certeza y, por tanto, en la claridad de los operadores respecto de las (in)conductas que (no) promueve el sistema. Esta

\footnotetext{
18 La Constitución dispone que los tribunales superiores de justicia, en uso de sus facultades disciplinarias, (solo) podrán invalidar resoluciones jurisdiccionales en los casos y forma que establezca la ley orgánica respectiva. A dichos efectos el Código Orgánico de Tribunales contempla el Recurso de Queja, que tiene por exclusiva finalidad corregir las faltas o abusos graves cometidos en la dictación de resoluciones de carácter jurisdiccional. Sobran palabras.
} 
Zapata - Carrera judicial. Lineamientos generales para un estatuto...

claridad en la predeterminación de los deberes facilita su promoción, a la vez que otorga legitimidad a la amplia gama de consecuencias asociadas al rendimiento por bajo de lo esperado. Estas consecuencias se regirán con preferencia por lógicas de incentivo del mejoramiento, y solo agotadas estas estrategias se activará si fuera el caso el segundo régimen, el sistema disciplinario, razón por la cual le denominamos de ultima ratio, debiendo además estar suficientemente provisto de garantías de debido proceso para el funcionario enjuiciado.

La desventaja es evidente. Radica en la imposibilidad de cubrir normativamente todas las situaciones, pues la casuística presente en la realidad supera siempre cualquier diseño técnico. Claro que la insuficiencia normativa es connatural a un modelo basado en principios éticos que constituyen un ideal regulativo $^{19}$. De esta desventaja, a nuestro juicio, no debe ocuparse directamente la autoridad de gobierno judicial (quien quiera que la encarne), sino que los propios afectados, es decir, jueces y juezas según su participación adhesiva a programas que promuevan las llamadas "virtudes judiciales", lo que debería acarrear progresivamente niveles de excelencia al alza.

En este contexto, la discusión acerca de la necesidad (y eficacia) de los códigos de ética y la (im)procedencia de los tribunales de ética puede ser reenfocada asumiéndose el fondo del problema -el comportamiento judicial debidocomo un conjunto de deberes enunciados en términos de ideal regulativo pero exigido (en el sentido de medido) en clave de evaluación del desempeño.

\section{2.i. Régimen de evaluación del desempeño}

Los actuales sistemas de evaluación del desempeño traducen mínimos éticos, por lo que hacen referencia exactamente al mismo asunto que las reflexiones éticas: la necesidad de que los operadores judiciales se comporten de una manera que se condiga con el logro de los bienes o metas de la función.

La distinción entre conducta y desempeño, la primera para abarcar los diversos deberes y prohibiciones del juez y la segunda básicamente para referirse al rendimiento o producción que mantiene el Código Orgánico de Tribunales y que objetamos, se explica en la introducción más bien reciente de las técnicas de evaluación del desempeño en los sistemas judiciales, proceso que fue incapaz de identificar, o al menos de integrar, esta categoría dentro de las alusivas a la conducta judicial. Así, se hizo natural entender que corrían por separado las exigencias de conducta o éticas y las exigencias del desempeño o de buenas prácticas,

\footnotetext{
${ }^{19}$ Ideal regulativo en sentido kantiano, como una meta de la que no sabemos teóricamente si alguna vez será posible, pero en cuya realización es moralmente racional emplear todas las fuerzas posibles, porque es un mandato de la razón perseguirlo, conceptualización extraída de Cortina, Adela: Ética Aplicada y Democracia Radical, 2001, p. 172, citando a Kant, Metaphysike der Sitten, VI, p. 354 (trad. cast. p. 194).
} 
traducidas las primeras en Códigos de Ética y en Manuales de Buenas Prácticas las segundas.

Nuestra propuesta invita a mirar el asunto sin prejuicios, sin el velo de las posiciones previas que fosilizan el análisis, para responder a la siguiente pregunta: ¿qué es un sistema de evaluación del desempeño con sus indicadores y medidores de gestión sino la particularización y medición de las conductas derivadas de deberes éticos de la función de juzgar?

Es en este entendido que proponemos un modelo de gestión del desempeño que desarrolle, con puentes de ida y vuelta, los deberes (éticos) derivados de la función de juzgar, en un sistema de evaluación capaz de poner los incentivos de forma tal que propicie la expedición de la decisión jurisdiccional en un proceso decisorio de calidad.

Este régimen de evaluación del desempeño debe poner sus resultados a disposición del Sistema de Carrera para las decisiones que se tomen en lo relativo al desplazamiento del funcionario por las diversas categorías del escalafón, pero debe encontrarse totalmente desconectado del Sistema de Nombramientos, el que recibirá, sin embargo, la información que requiera por medio de los delimitados procedimientos de postulación a los diversos cargos vacantes de manos de los propios interesados.

Nuestro régimen de evaluación del desempeño posee una matriz que debería estar desarrollada a nivel de principios en la ley, sirviéndonos como modelo posible el Código Iberoamericano de Ética Judicial, que explicita los que hemos denominado deberes periféricos de la función judicial, los que coinciden con los principios de ética judicial universalmente aceptados.

La caracterización básica de un sistema de evaluación del desempeño en la discusión actual supone: $:^{20}$

a) Que los Estados cuenten con un mecanismo justo y rodeado de garantías para evaluar el desempeño de los jueces;

b) Que la evaluación no se dirige a la persona del juez, sino a su desempeño en el ejercicio de la función jurisdiccional. Nunca debe inmiscuirse en la vida privada del juez, ni en su intimidad, ni menoscabará los derechos y libertades fundamentales del juez como persona. Tampoco la evaluación ha de rozar lo que el juez decidió en el ejercicio independiente de la función jurisdiccional, sino que se dirigirá a los aspectos externos de su desempeño. La evaluación no ha de atender al sentido en el que el juez resolvió, que quedará en el ámbito

20 http://www.cumbrejudicial.org/web/guest/referentes_internacionales_de_Justicia: Documento de Sustentación VII Cumbre Iberoamericana de Presidentes de Cortes Supremas y Tribunales Superiores de Justicia. 
Zapata - Carrera judicial. Lineamientos generales para un estatuto...

intangible del ejercicio independiente de la función jurisdiccional y solo puede ser revisado por otros tribunales en el ejercicio de la misma función; y

c) Que la evaluación debe propender al mejoramiento del desempeño de cada juez y del ejercicio de la función jurisdiccional del Estado en su conjunto, estimulando el progreso en la capacitación profesional de los jueces y la afirmación de su independencia y demás valores éticos e intelectuales.

Estas premisas determinan que la evaluación del desempeño debe ser concebida como un sistema de mejora de la actividad judicial y de apoyo al trabajo del juez, contribuyendo a fortalecer la eficiencia, eficacia y calidad de la administración de justicia.

Como hemos dicho, nuestro modelo se orienta por -a la vez que traducelos deberes éticos de la función de juzgar. En lo tocante al régimen de evaluación del desempeño consiste en un sistema de medición de las pautas de conductas del juez comparadas con un estándar predefinido, desde el normal desenvolvimiento hasta la excelencia. Los resultados de esta comparación traen consecuencias para el juez evaluado, también predeterminadas, que pueden ser positivas, negativas u otras que sin reunir necesariamente las características de aquellas, se contemplen como posibles dentro de determinados rangos de resultados, por ejemplo: charlas vocacionales, motivacionales o simplemente capacitaciones ordinarias.

Dentro de las consecuencias positivas pueden figurar los bonos de gestión, becas, puntos a favor para la promoción en las categorías del escalafón en el Sistema de Carrera, permisos especiales para labores académicas o de capacitación, etcétera.

El resultado deficiente del juez evaluado, por su parte, según su entidad, ha de admitir en sus estrategias de mejora las capacitaciones, terapias ocupacionales, exploraciones vocacionales y técnicas motivacionales, y solo agotadas y frustradas en sus expectativas estas posibilidades se activará el sistema disciplinario, razón por la cual le denominamos de ultima ratio.

\section{2.ii. Sistema disciplinario}

La disciplina se activa, en nuestro modelo, por dos vías: una de ellas es la resultante del envío de información del régimen de evaluación del desempeño que ha detectado, a partir de sus medidores e indicadores, un grado de deficiencia relevante en el cumplimiento de las metas $\mathrm{y} / \mathrm{u}$ objetivos predeterminados $\mathrm{y}$ frustración en los resultados de las estrategias de mejoramiento disponibles para el caso en particular. La segunda vía es la activación directa por posible infracción de los deberes y prohibiciones que se contemplen taxativamente en la legislación. Nuestra propuesta, desde luego, es contraria a cláusulas amplias alusivas a 
conductas personales, especialmente si aluden a etiquetas del tipo decoro de la magistratura. $^{21}$

Las conductas ilícitas deben estar graduadas de acuerdo con su gravedad y, así, demarcadas las posibles sanciones según su mayor o menor entidad. Las sanciones también deben estar predeterminadas, desde las menores a aquellas que signifiquen separación del cargo. La posibilidad de suspensión de funciones debe contar con una estricta reglamentación orientada por el principio de proporcionalidad, a fin de que sea procedente solo en faltas de extrema gravedad.

El procedimiento debe ajustarse a las exigencias de un debido proceso y, en particular, a los derechos de audiencia, defensa, contradicción y recursos legales que correspondan. Se estima como nota básica del procedimiento el que la acusación quede en manos de un investigador o instructor, quien formulará los cargos o solicitará sobreseimiento según el mérito de la investigación y no participará de la decisión condenatoria o absolutoria definitiva. La investigación no podrá exceder el plazo de treinta días y la duración total del proceso no más de tres meses.

En cuanto al órgano que deberá conocer la causa seguimos la directriz propuesta por la Convención Nacional de la Asociación Nacional de Magistrados de Chile de 2007, que propone el establecimiento de un tribunal accidental con un procedimiento para la determinación de los miembros que en cada caso asumirán el conocimiento del asunto. Agregamos por nuestra cuenta lo siguiente:

a) Lo central es la confección periódica de una Nómina compuesta de un número determinado de miembros (por ejemplo 50 nombres), elegidos directamente por los posibles afectados de las diversas listas que pudieran ser propuestas por las organizaciones naturales existentes en el servicio. El perfil del integrante de la nómina debiera ser la de un juez prestigiado al interior del sistema por poseer sobresalientes características de imparcialidad, ponderación y capacidad.

b) Para cada caso debería sortearse de esta Nómina un instructor de la causa y un primer tribunal para conocer la causa en primera instancia y, luego, si se

\footnotetext{
21 González Granda, Piedad: Independencia del Juez y Control de su Actividad, 1993, p. 193, citando a Andrés Ibáñez/Movilla Álvarez: El Poder Judicial, Madrid, 1986: Hay ciertos cuestionamientos doctrinarios acerca de la funcionalidad de esta responsabilidad (disciplinaria), entendiendo que lo que necesita la independencia judicial es una amplia y estricta responsabilidad civil y penal, sin embargo en la actualidad surge una corriente contraria que aboga incluso por un endurecimiento y mayor utilización de los mecanismos de responsabilidad disciplinaria, pero con supresión de la responsabilidad por conductas personales (únicamente tendentes al decoro o prestigio de la magistratura, medidos con criterios subjetivos), entendiéndose que "un criterio que debe inspirar directamente la interpretación de todas las descripciones típicas, no siempre demasiado precisas en su formulación, es que solo pueden entenderse en función de bienes jurídicos tales como la imparcialidad, la diligencia y el cuidado que exigen la adecuada prestación del servicio público”.
} 
Zapata - Carrera judicial. Lineamientos generales para un estatuto...

interpusiere un recurso, la integración de un segundo tribunal que revisará lo decidido.

c) Finalmente cabría considerar un recurso extraordinario ante la Corte Suprema a activarse solo a instancias del sancionado y en casos específicamente delimitados para la aplicación de sanciones graves y destitución. Cabe precisar que en este caso la Corte Suprema no estaría actuando como órgano de gobierno, sino que como tribunal jurisdiccional ante el cual pueda acudir el juez como cualquier ciudadano que se estime afectado en sus derechos.

d) Los miembros del Tribunal podrán ser recusados o inhabilitados según causales predeterminadas, caso en que se deberá proceder a un nuevo sorteo para completar el Tribunal.

e) No formarán parte de este Tribunal miembros de tribunales de la jurisdicción de la Corte a la que pertenece el afectado.

La noción de un tribunal "accidental" conformado en primera instancia por jueces no pertenecientes a la jurisdicción del investigado, con mecanismos de recusaciones e implicancias, asegura la conformación de un tribunal imparcial. Y la idea de obtener la nominación de los miembros del tribunal por sorteo, adjudicando al designado una carga "comunitaria", provee al sistema de altas dosis de legitimidad. Este último punto no es menor frente al sistema disciplinario actualmente vigente que presenta una fuerte crisis de legitimidad al estar depositado en jueces que en calidad de superiores del encausado revisan sus resoluciones jurisdiccionales, lo que encierra una amenaza permanente a la independencia judicial. Constituido el tribunal por jueces de un territorio jurisdiccional diverso al del encausado el problema desaparece de raíz.

\section{2.iii. Dos palabras acerca de la autorregulación ética}

En el modelo de gestión del desempeño que proponemos detectamos como ventaja la predeterminación de las exigencias de conducta mediante la fijación de indicadores, estándares o valores de referencia para la acción y determinación de las consecuencias asociadas a los resultados, con eventual activación del régimen disciplinario a su alarma por las deficiencias. Pero también advertimos de la desventaja que implicaba la imposibilidad de cubrir todos los aspectos deseables del desempeño judicial.

Parece indispensable hacerse cargo de este tema connatural a un modelo de control como el que proponemos, en el que posee especial relevancia la ética judicial que no se agota en el plano de las normas. Por el contrario, decimos con Atienza22 que el concepto de buen juez no se deja definir exclusivamente en términos normativos. El buen juez no es simplemente el que cumple ciertas normas de conducta (y no incurre en responsabilidad penal, civil o disciplinaria), sino el que ha desarrollado profesionalmente ciertos rasgos de carácter que constituyen las virtudes judiciales.

22 Atienza, Manuel: "Ética Judicial”, en del mismo, Cuestiones Judiciales, p. 153. 
La fórmula para superar esta desventaja consiste en acoplar una tercera dimensión, que de algún modo implica la superación de la contraposición entre una ética del deber basada en la obediencia de nomas, y una ética de las virtudes basada en la formación del carácter y en la educación de los sentimientos para disponer a las personas hacia el bien, contraposición que es uno de los tópicos más discutidos en la teoría ética contemporánea. ${ }^{23}$ Esta tercera dimensión supone la autorregulación ética basada en la educación en las virtudes judiciales. Una virtud es una cualidad humana adquirida, cuya posesión y ejercicio tiende a hacernos capaces de lograr aquellos bienes que son internos y cuya carencia nos impide efectivamente el lograr cualquiera de tales bienes. ${ }^{24}$ Las virtudes necesitan de una práctica y de una comunidad donde pueda haber bienes internos, concluye Atienza. Agregamos por nuestra cuenta que esa comunidad puede estar articulada por las organizaciones naturales de los jueces, esto es, las asociaciones de magistrados o movimientos internos de jueces, y en particular sus centros de estudios como espacios privilegiados de reflexión y debate, a los que estimamos de mayor interés sumar las organizaciones de igual naturaleza asentadas por fuera del orden judicial pero en estrecha conexión con este, como las propias de los fiscales, defensores, Colegio y asociaciones de abogados y centros académicos relacionados. En esta perspectiva, cobra especial relevancia la creación de comités consultivos sobre aspectos de ética funcionaria con capacidad de emitir dictámenes que sirvan de guía a la acción de los jueces. Esta dimensión no puede apoyarse en fórmulas coercitivas, sino que en la persuasión, el ejemplo y liderazgo de quienes presenten un mayor desarrollo vocacional, en iniciativas innovadoras e incluso entretenidas ${ }^{25}$ como el cine y la literatura y, desde luego, jornadas de reflexión.

\section{A modo de cierre}

En el modelo que hemos propuesto la Carrera Judicial es un sistema de perfeccionamiento profesional sujeto a reglas de ingreso, permanencia y desplazamiento de los funcionarios judiciales en las diversas categorías del Escalafón, donde el acceso a cada una de las categorías exige una serie de requisitos relativos a permanencia en la categoría inmediatamente anterior, nivel de capacitación y resultado del desempeño funcionario. Una vez conseguidas, las categorías proporcionan al juez diversas prerrogativas a la vez que ciertas condiciones estatutarias para postular a los cargos vacantes, según las exigencias propias de la relación unívoca entre cargo-categoría.

\footnotetext{
${ }^{23}$ Atienza, Manuel: "Virtudes Judiciales sobre la Selección y Formación de los Jueces en el Estado de Derecho", en del mismo, Cuestiones Judiciales, p. 136.

${ }^{24}$ MacIntyre, Alasdair.: Tras la virtud, 1987. Citado por Atienza, Manuel: ibid., p. 138.

25 Atienza, Manuel: Ibid., p. 144, cree el autor que en la enseñanza de las virtudes judiciales, el cine y, sobre todo, la literatura podrían jugar un papel de cierta importancia.
} 
El subsistema de Capacitación constituye la esencia del modelo y está destinado a articular la provisión de los conocimientos y destrezas atingentes a los operadores según función actual y futura. Su alianza con el subsistema de Gestión del Desempeño, que entrega información sobre el desempeño funcionario, pone a disposición del juez todos los recursos para que desarrolle su vida profesional y, de acuerdo con sus méritos, obtenga las prerrogativas estatutarias que fueren del caso.

Como dijimos, los puntos o créditos para avanzar en las categorías se obtienen de los dos subsistemas del Modelo de Carrera, Capacitación y Gestión del Desempeño. Su alianza contribuye a crear un sistema de mejoramiento continuo, pues tendrá a funcionarios permanentemente preocupados de su más $y$ mejor, es decir, de obtener más capacitación y mejor resultado en su desempeño.

Y para el que no esté interesado en desplazarse hacia nuevas categorías o simplemente haya llegado a la que le interesa, deben existir reglas para la defensa de su permanencia en el nivel, a fin de impedir que el funcionario se sienta liberado de su obligación de mejorar. Para ello deberá certificar un mínimo de capacitación al estilo de lo que hoy existe en el sistema de perfeccionamiento de la Academia Judicial, que exige un curso anual según elección de materia y, por otro lado, un resultado estimado al menos Bueno en el ámbito de su desempeño funcionario en cada período.

Las prerrogativas que conceden las diversas categorías en un modelo como el que proponemos no deben limitarse a mejoras económicas, sino que deben atender a una variedad de posibilidades que por sí mismas constituyan alicientes para el desplazamiento. Sin embargo, el sistema debe contemplar estrategias de contención, a fin de que no se copen de inmediato las categorías más codiciadas.

Sobre las posibilidades de incentivos se encuentran, además de los económicos, los constitutivos de becas y permisos para postgrados, adicionales de vacaciones y, en los niveles más significativos, permisos con medio goce de sueldo sin expresión de causa por períodos que el sistema estime razonables.

La contención que el sistema debe proveer para evitar que se copen las categorías más atractivas debe estar encaminada a generar brechas significativas entre los niveles, a fin de que no sean de fácil acceso, en lo tocante a las capacitaciones y resultados de desempeño.

Finalmente, no debe olvidarse que nuestro modelo de Carrera Judicial propugna una relación con el sistema de Nombramientos que es unívoca -de vinculación no recíproca-, lo que significa que si bien se puede conseguir una categoría sin respecto de cargo determinado (lo que implica que un juez de garantía puede ejercer de tal y sin embargo llegar a obtener una categoría a la que se asocian importantes prerrogativas, por ejemplo la decimotercera 
categoría) existirán en el sistema cargos que exijan determinadas categorías, y por tanto el Sistema de Nombramientos exigirá su acreditación a la hora de participar de un proceso de selección para ese cargo vacante. Así, solo los funcionarios que han obtenido las categorías más significativas del sistema podrán postularse a los cargos vacantes de mayor responsabilidad.

Ambos subsistemas (Capacitación y Gestión del Desempeño) entregan información a las reparticiones de Carrera y de Nombramientos, pero se relacionan con ellas de forma radicalmente diferente. Es así como respecto del Sistema de Carrera poseen una relación directa y permanente al figurar como subsistemas de aquel, constituyendo su soporte estructural. En cambio, con el Sistema de Nombramientos mantienen una relación contingente y mediada por la decisión del funcionario de postularse a un cargo vacante, de modo que habiendo sido nombrado un funcionario en propiedad una vez en su vida funcionaria en un cargo determinado, podría suceder que no hubiera una segunda vez en la que este se relacione con el Sistema de Nombramientos, si el funcionario en cuestión decide no postular a nuevos cargos vacantes y mantenerse para el resto de su vida laboral en la misma función. Este funcionario, sin embargo, no podrá eludir las exigencias permanentes de los subsistemas de Capacitación y Gestión del Desempeño que mantienen, como hemos dicho, una relación directa y permanente con el Sistema de Carrera.

Es evidente que la implementación de este modelo debe contemplar una definición acerca del órgano de gobierno global bajo el cual operarán las diversas oficinas o comités técnicos de administración del Sistema de Carrera y, por otro lado, del Sistema de Nombramientos que, como hemos dicho, funciona de forma autónoma del primero. Nuestra definición básica en este punto está referida a la necesidad de que el gobierno judicial se entregue a un órgano técnico autónomo, suprimiendo toda intervención de los Plenos de las Cortes (Suprema y de Apelaciones), las que deben estar dedicadas en exclusivo a funciones jurisdiccionales. ${ }^{26}$

Un sistema de este tipo instala la idea de reconocimiento como acicate para el logro de mejores categorías, pero no devalúa la vocación constriñendo al funcionario a un ascenso para la obtención de prerrogativas. Logra niveles de excelencia en alza, pues propicia un proceso permanente de mejoramiento. Así, nuestra propuesta de reformulación de la estructura organizacional de los

\footnotetext{
${ }^{26}$ Ello no quiere decir, desde luego, que a los jueces les quede vedado su integración en los comités técnicos o en el mismo órgano global de gobierno. Lejos de eso, nuestra perspectiva propicia su participación que estimamos debe ser representativa y proporcional respecto de los diversos niveles del escalafón, preferentemente con decisión democrática de los mismos jueces, sobre la base de la acreditación de las competencias propias del cargo, quienes una vez en estas funciones cesarán las propiamente jurisdiccionales por el período correspondiente. Un modelo como el de la Conferencia Judicial Norteamericana aparece como un modelo que valdría la pena estudiar a estos efectos.
} 
Zapata - Carrera judicial. Lineamientos generales para un estatuto...

tribunales chilenos aspira a garantizar institucionalmente su función central y periférica: la expedición de una decisión con sujeción a la ley, integrando al proceso decisorio los deberes éticos de la función de juzgar, propiciando un resultado de calidad. 
REJ - Revista de Estudios de la Justicia - No 18 - Año 2013

\section{BIBLIOGRAFÍA}

* FLORES Monardes, Álvaro: "Gobierno Judicial: el caso chileno. La reforma olvidada", en Revista de Estudios de la Justicia Nº 6, Facultad de Derecho Universidad de Chile, 2006.

* AlDUNATE Lizana, Eduardo: "La constitución Monárquica del Poder Judicial", en Revista de Derecho XXII, Universidad Católica de Valparaíso, 2001.

* ATIENZA, Manuel: "Ética Judicial", en Cuestiones Judiciales, Distribuciones Fontamara S.A., México, 2001.

"Virtudes Judiciales sobre la Selección y Formación de los Jueces en el Estado de Derecho", en Cuestiones Judiciales. Distribuciones Fontamara S.A., México, 2001.

* ATRIA, Fernando. "La improbabilidad de la jurisdicción", en La Judicatura como organización, Couso Salas y Atria Lemaitre (ed.), Expansiva, Santiago, Chile, 2007.

"Jurisdicción e Independencia Judicial. El Poder Judicial como Poder Nulo", en Revista de Estudios de la Justicia No 5, Facultad de Derecho Universidad de Chile, 2005.

* CORTINA, Adela: Ética Aplicada y Democracia Radical, Tecnos, 3ªdición, Madrid, 2001.

* GONZÁleZ Granda, Piedad: Independencia del Juez y Control de su Actividad, Ed. Tirant lo Blanch, España, 1993.

* VARGAS, Juan Enrique: "Alternativas para estructurar el gobierno judicial respetando la independencia de los jueces", en La Judicatura como organización, Couso Salas y Atria Lemaitre (ed.), Expansiva, Santiago, Chile, 2007. 